\title{
Histopathologic observations on the persistence of Mycobacterium leprae in the skin of multibacillary leprosy patients under chemotherapy
}

\author{
K R WABITSCH* \& W M MEYERS $†$ \\ * Bernhard-Nocht-Institut, Hamburg, Federal Republic of Germany; \\ $\dagger$ Armed Forces Institute of Pathology, Washington DC 20306, US A
}

\begin{abstract}
Accepted for publication 11 May 1988
Summary In the study of 782 biopsy specimens from 195 patients during and after chemotherapy we compared the numbers of Mycobacterium leprae stained by the Fite-Faraco (FF) and the Gomori methenamine-silver (GMS) techniques. In many patients large amounts of non-acid-fast $M$. leprae or remnants thereof remained 66 months af ter starting effective multidrug therapy. The GMS stain is a useful method for assessing the efficacy of methods for enhancing bacillary clearance in multibacillary leprosy patients.
\end{abstract}

\section{Introduction}

The Fite-Faraco (FF) stain, or modifications thereof, is used routinely to demonstrate Mycobacterium leprae in tissue sections. ${ }^{1}$ As the $M$. leprae degenerate in the host, either naturally, or in response to therapy, acid-fastness diminishes and is eventually lost even though whole carcasses of the bacilli and/or bacillary remnants persist. ${ }^{2}$ The silvering of leprosy bacilli in tissues was first described in 1948. ${ }^{3}$ The Gomori methenamine-silver (GMS) method, ${ }^{4}$ as employed by Grocott ${ }^{5}$ for fungi, appears to stain all $M$. leprae in tissues, whether or not they have lost their acid-fastness. ${ }^{2,6} \mathrm{We}$ present here the results of observations on multiple biopsy specimens from 195 treated patients followed over a period of up to 66 months.

\section{Methods}

The data reported here are from multibacillary patients in a prospective multicentre multidrug chemotherapy trial in Pakistan (Karachi), India (Bombay, Chetput, Madras) and Sierra Leone (Freetown). Histopathologic classification was according to Ridley-Jopling, ${ }^{7}$ and was the criterion used in dividing the patients into borderline-lepromatous $(\mathrm{BL})$, subpolar lepromatous $\left(\mathrm{LL}_{\mathrm{s}}\right)$, and polar lepromatous $\left(L_{\mathrm{p}}\right)$. Three hundred and seven patients entered the study, but data for this report are from only 195 patients who had multiple skin biopsies stained by both the FF and GMS methods. All patients were treated for 3 years with one of the following drug regimens: DDS (100 $\mathrm{mg} / \mathrm{da}) ; \mathrm{DDS}(100 \mathrm{mg} / \mathrm{da})+$ rifampicin $(600 \mathrm{mg} / \mathrm{da})$; Isoprodian $(2 \mathrm{tabs})+$ rifampicin $(100 \mathrm{mg} / \mathrm{da})$. 
Table 1. Semiquantitative grading scale for $M$. leprae in skin biopsies, for FF and GMS staining

\begin{tabular}{lll} 
Grade & Number of bacilli & Comparative BIG* \\
\hline 1 & none & - \\
2 & rare/occasional & $1+$ \\
3 & few & $2+$ \\
4 & moderate & $3+$ to $4+$ \\
5 & large & $5+$ to $5 \cdot 5+$ \\
6 & massive & $6+$ to $6 \cdot 5+$ \\
\hline
\end{tabular}

* This is an estimation. These values of the Bacterial Index of Granuloma (BIG) are as described in Ridley, DS, Skin Biopsy in Leprosy (Documenta Geigy), Ciba-Geigy, 2nd ed. Basle, Switzerland, 1985, pp. 59-60.

One tablet Isoprodian contains $50 \mathrm{mg}$ DDS, $175 \mathrm{mg}$ INH and $175 \mathrm{mg}$ prothionamide. We report on findings in 1504 biopsy specimens taken at approximately 6 months to 1-year intervals over a 66month period.

Sections from all specimens were stained by a routine $\mathrm{FF}^{1}$ method and 782 of the same specimens were stained by the GMS ${ }^{8}$ technique. Sections were stained by GMS usually only af ter 18-24 months of therapy. All sections were processed in the same laboratory at the Armed Forces Institute of Pathology (AFIP). The numbers of bacilli in all FF and GMS sections were graded semiquantitatively by the same observer (WMM) (Table 1). Using the assigned values of 1 to 6 designated in Table 1, means were calculated for the bacillary density in both FF and GMS stained sections. Each mean represents evaluations of specimens of 10 or more patients. Regression analyses were performed and correlation coefficients calculated. Testing for significance between differences of means was by the Signed Rank Test.

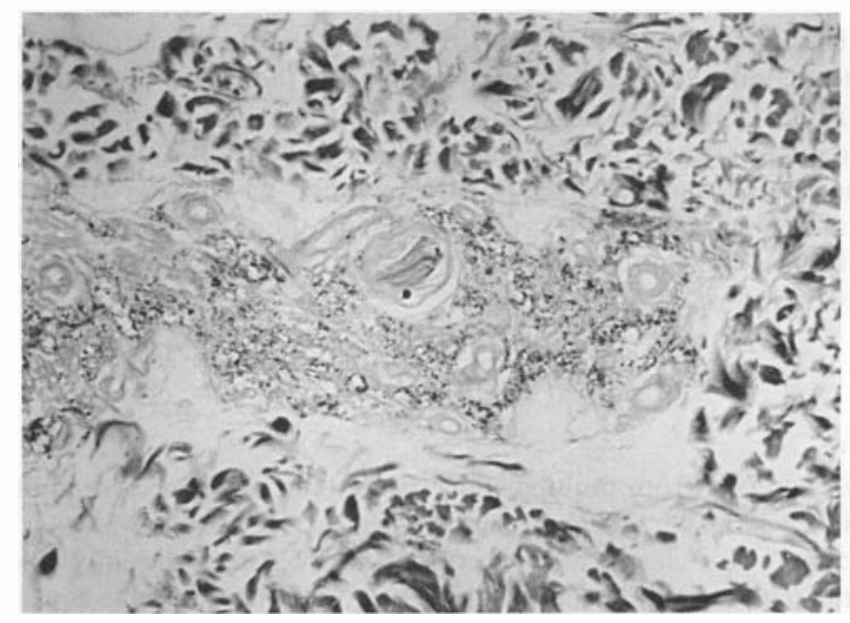

Figure 1. Skin of a subpolar lepromatous patient treated with DDS plus rif ampicin for 36 months. This specimen was taken 13 months after cessation of therapy. Note the large amounts of silvered (black deposits) bacillary material in the histiocytes, and smaller amounts in the nerve. Fite-Faraco stained parallel sections did not reveal acid-fast bacilli. GMS stain, × 250. (AFIP Neg. 87-6570). 




Figure 2. GMS grading in 533 AFB positive specimens.

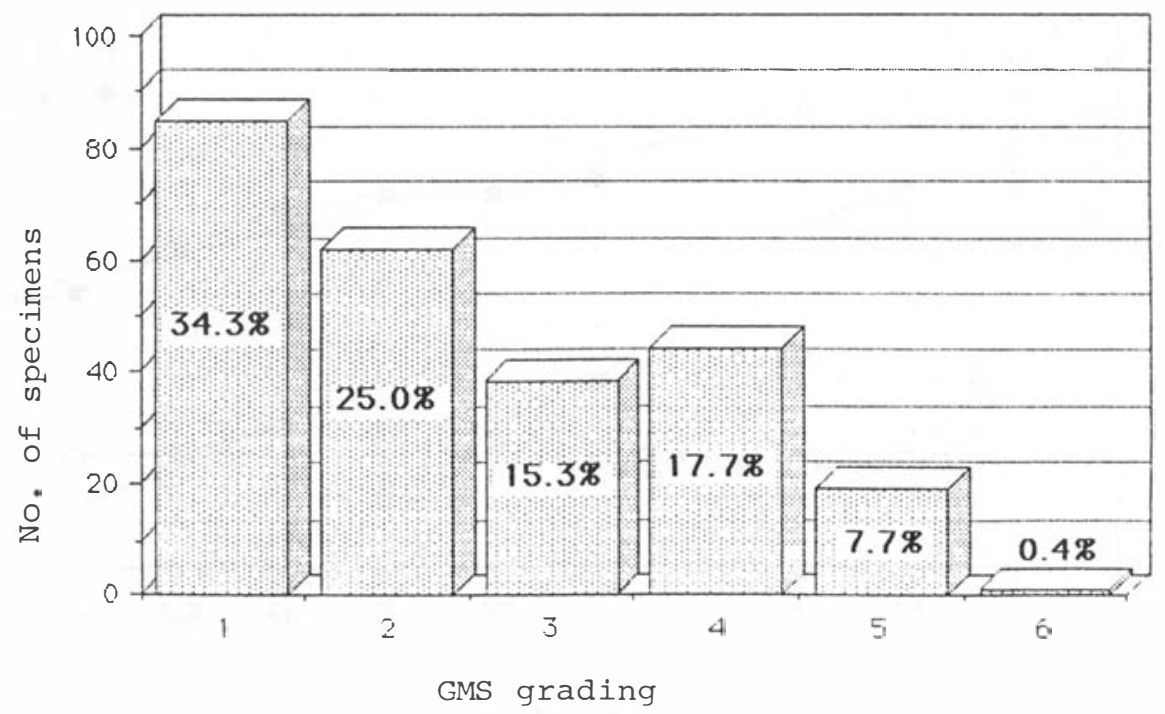

Figure 3. GMS grading in 248 AFB negative specimens (for details of grading see Table 1).

\section{Results}

Figure 1 illustrates silvered $M$. Leprae in a GMS stained section of an $L^{2}$ patient 13 months after completing 3 years therapy with DDS + rifampicin.

Of the 782 specimens studied by both the FF and GMS stain, 533 were positive for acid-fast bacilli (AFB): $112(21 \%)$ had identical numbers of organisms in the FF and GMS stained sections, and in $421(79 \%)$, the GMS gave higher yields of bacilli (Figure 2). In the 248 sections that revealed 


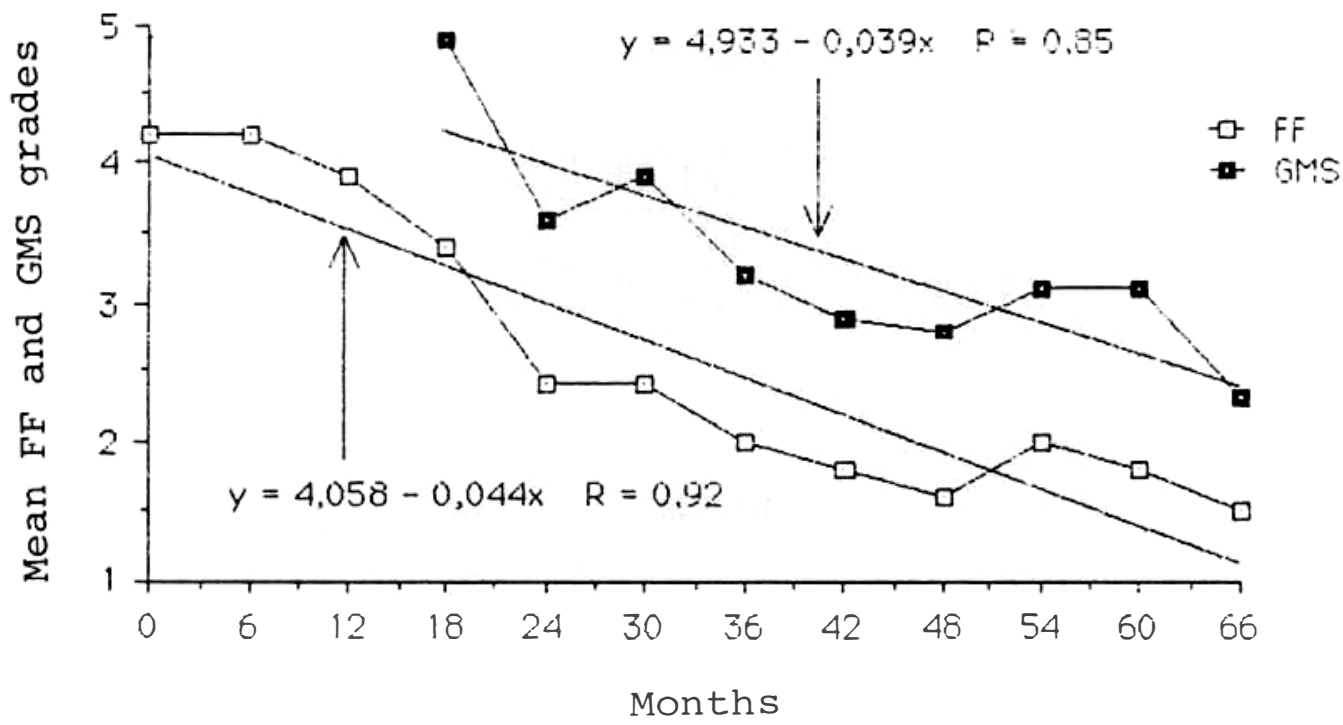

Figure 4. Mean FF and GMS grades during and after treatment in $\mathrm{LL}_{\mathrm{p}}$ patients.

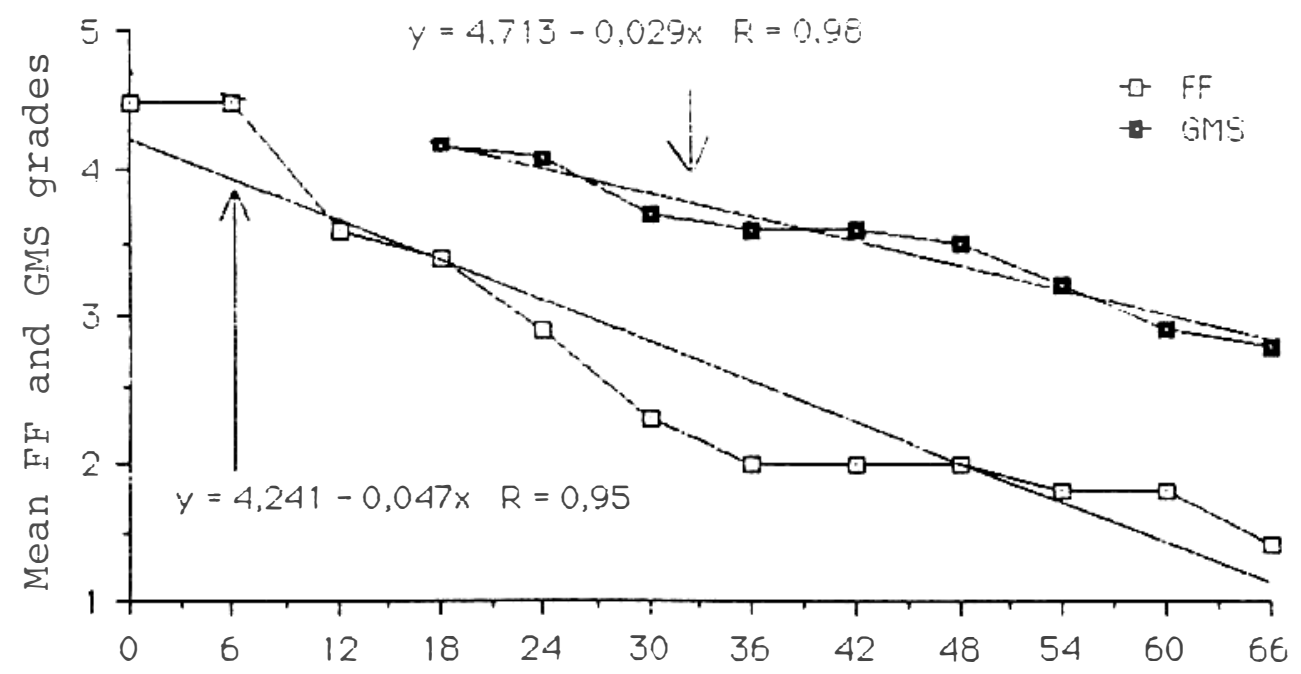

Months

Figure 5. Mean FF and GMS grades during and after treatment in $\mathrm{LL}_{\mathrm{s}}$ patients.

no AFB in FF sections, 84 (33.9\%) were GMS-negative, and 164 (66.1\%) were GMS-positive, with differences ranging from 1 to 5 grades (Figure 3).

Changes in the numbers of $M$. leprae in the tissue sections over the 66-month period of observations in the $\mathrm{LL}_{\mathrm{p}}, \mathrm{LL}_{\mathrm{s}}$, and $\mathrm{BL}$ patients were evaluated. Regression analyses show linear downward regressions for both staining techniques in all three groups of patients (Figures 4-6). The closest fit $(r=0.98)$ was in the specimens from $L_{\mathrm{s}}$ patients stained by the GMS (Figure 5). The 


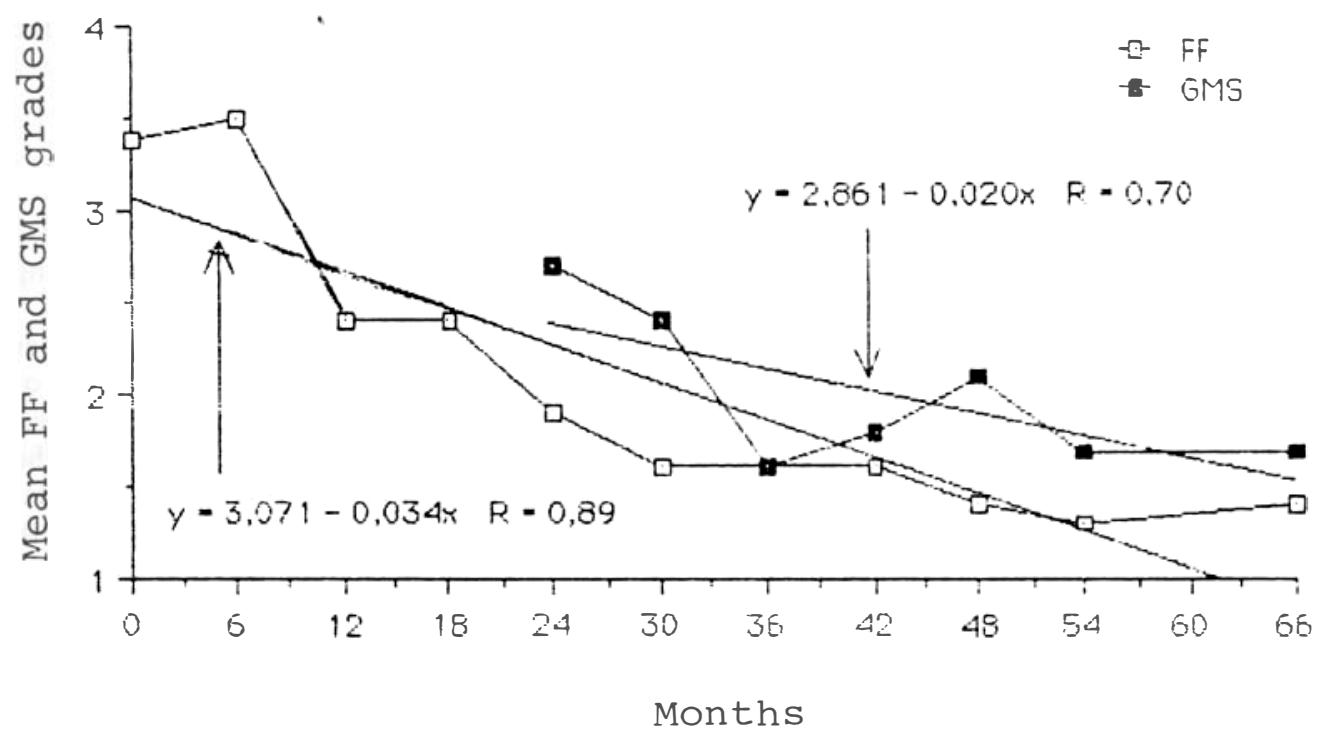

Figure 6. Mean FF and GMS grades during and after treatment in BL patients.



Figure 7. Difference of mean FF and GMS grades at 24 and 66 months for $\mathrm{LL}_{\mathrm{p}}$, $\mathrm{LL}_{\mathrm{s}}$, and BL patients.

GMS sections consistently show larger numbers of organisms than the FF stains. These differences are statistically significant $(p<0 \cdot 05)$ for $\mathrm{LL}_{\mathrm{p}}, \mathrm{LL}_{\mathrm{s}}$, and $\mathrm{BL}$ patients.

The negative slope of the FF line as compared to the GMS line is always more pronounced, leading to an increase in the difference of the FF and GMS grade means over time (Figure 7). The greater divergence of the regression in $\mathrm{LL}_{\mathrm{s}}$ and $\mathrm{BL}$ patients (Figures 5 and 6) suggests that $\mathrm{LL}_{\mathrm{s}}$ and BL patients are slightly more efficient than $L_{\mathrm{p}}$ patients in diminishing the acid-fastness of $M$. leprae. 
There was no difference in the degree or duration of persistence of carcasses of $M$. leprae in the three different treatment regimens used in this chemotherapy trial.

\section{Discussion}

This large-scale study demonstrates the persistence of carcasses and bacillary debris of $M$. leprae long after they have lost their acid-fastness. The persisting carcasses and debris are continuing sources of antigen which contribute to the morbidity, e.g. erythema nodosum leprosum.

The acid-fastness of $M$. leprae is weaker than for other mycobacteria, but as in the other mycobacteria the acid-fastness is related to mycolic acid in the cell wall. ${ }^{9}$ The mode of action of methenamine-silver staining is not completely understood, but, in part, depends on the hydrolysis of saccharides to yield aldehyde groups. The silver of the stain is then reduced by the aldehyde of the hydrolysed carbohydrate. ${ }^{10}$ Reducing lipids could produce a similar result. Thus, the differential staining of degenerating $M$. leprae suggests that the integrity of the mycolic acids is lost long before the carbohydrate (or lipid components) of the cell wall lose their reducing properties. The identity of the persisting cell wall components is unknown. Immunohistochemical studies with specific antibodies may be useful in the in situ identification of the persisting cell wall material, and may provide information on the intracellular digestion of $M$. leprae.

Enhancement of the removal of persisting bacillary material in multibacillary patients (e.g. immunotherapy) is an objective of more effective therapy of leprosy. The GMS stain provides a simple technique for following the efficacy of such treatment modalities as may become available.

\section{Acknowledgments}

The following participated in other clinical or laboratory aspects of the multicentre chemotherapy trial: M. Aschhoff, G. D. Burchard, Th. Chiang, V. Devanbu, M. Dietrich, S. Engelhorn, R. Ganapati, P. Irudayaraj, J. Jayakumar, P. Kern, U. Laukamm-Josten, M. Peters, R. Pfau, J. and M. Rangaraj, and L. Revankar. The histopathologic assistance of Isaac Banks is gratefully acknowledged.

This study was supported in part by the German Leprosy Relief Association (DAHW), Würzburg, Federal Republic of Germany, and the American Registry of Pathology at the Armed Institute of Pathology, Washington DC.

\section{References}

1 Luna LG (ed.). Manual of Histologic Staining Methods of the Armed Forces Institute of Pathology. 3rd ed. New York: McGraw-Hill Book Co., 1968, pp. 217-18.

${ }^{2}$ Krieg RE, Meyers W M. Demonstration of Mycobacterium leprae in tissues from 'bacteriologically negative' treated lepromatous leprosy patients. Int J Lepr, 1979; 47: 367.

3 Blanco FL, Fite GL. Silvering of lepra bacilli in tissues. Arch Pathol, 1948; 46: 542-9. Reprinted in Int J Lepr, 1949; 17: 442-7.

${ }^{4}$ Gomori G. New histochemical test for glycogen and mucin. Am J Clin Path, 1946; 10: 177-9.

${ }^{5}$ Grocott RG. A stain for fungi in tissue sections and smears, using Gomori's methenamine-silver nitrate technique. Am J Clin Path, 1955; 25: 975-9.

${ }^{6}$ Sutter E, Roulet, FC. Staining Mycobacterium leprae in paraffin sections by the Gomori methenamine-silver method. Stain Technol, 1965; 40: 49-51.

7 Ridley DS, Jopling WH. Classification of leprosy according to immunity. A five-group system. Int J Lepr, 1966; 34: 255-73.

${ }^{8}$ Luna LG (ed.). Manual of Histologic Staining Methods of the Armed Forces Institute of Pathology, 3rd ed. New York: McGraw-Hill Book Co., 1968, pp. 230-2.

${ }^{9}$ Barksdale L, Kim KS, Mycobacterium. Bacteriol Rev, 1977; 41: 217-372.

${ }_{10}$ Thompson SW. Selected Histochemical and Histopathological Methods, Springfield, Ill: Charles C. Thomas, 1966, pp. 467-71. 